\title{
Digestive Pathologies during Chronic Renal Failure in the Nephrology and Haemodialysis Department at the University Hospital Center of Point G in Mali
}

\author{
${ }^{1}$ Nephrology Unit of the Fousseyni DAOU Hospital, Kayes, Mali \\ ${ }^{2}$ Nephrology and Haemodialysis Department of the CHU of Point G, Bamako, Mali \\ ${ }^{3}$ Faculty of Medicine of Bamako, University of Bamako, Bamako, Mali \\ ${ }^{4}$ Nephrology Unit of Mali GAVARDO Hospital, Bamako, Mali \\ ${ }^{5}$ Nephrology Unit of the Sikasso Regional Hospital, Sikasso, Mali \\ ${ }^{6}$ Nephrology Unit of the Mother and Child Hospital, The Luxembourg, Bamako, Mali \\ ${ }^{7}$ Internal Medicine Service of the University Hospital Center of Point G, Bamako, Mali

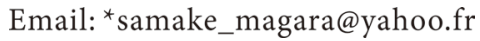

Magara Samaké1,2*, Seydou Sy,,3, Hamadoun Yattara',3, Moctar Coulibaly4, Mamadou Badou Sanogo², Aboubacar Sidiki Fofana2, Aboudou Messoum Dolo5, Djénéba Maiga5, Djénéba Diallo2,3, Atabieme Kodio², Bakary Diarra', Karamoko Djiguiba'6, Djibril Sy7, Saharé Fongoro',3

How to cite this paper: Samaké, M., Sy, S., Yattara, H., Coulibaly, M., Sanogo, M.B., Fofana, A.S., Dolo, A.M., Maiga, D., Diallo, D., Kodio, A., Diarra, B., Djiguiba, K., Sy, D. and Fongoro, S. (2020) Digestive Pathologies during Chronic Renal Failure in the Nephrology and Haemodialysis Department at the University Hospital Center of Point G in Mali. Open Journal of Clinical Diagnostics, 10, 41-48.

https://doi.org/10.4236/ojcd.2020.101004

Received: December 24, 2019

Accepted: February 11, 2020

Published: February 14, 2020

Copyright (๑) 2020 by author(s) and Scientific Research Publishing Inc. This work is licensed under the Creative Commons Attribution International License (CC BY 4.0).

http://creativecommons.org/licenses/by/4.0/

\begin{abstract}
Introduction: Chronic kidney disease (CKD) is the progressive and irreversible loss of kidney function. It exposes to many complications, among which, digestive complications. In Mali, we do not have data on the prevalence of digestive pathologies in people with chronic renal failure, hence the interest of this study. Objective: To determine the prevalence of digestive pathologies and to describe their manifestations during chronic renal failure. Patients and Methods: This was a prospective cross-sectional study conducted from September 2016 to August 2017, a period of 12 months. Included were patients hospitalized in our department with CKD who received digestive endoscopy and/or liver serology. Results: Seventy-one patients underwent digestive endoscopy with oesogastroduodenal fibroscopy (60 patients), rectoscopy (6 patients) and anoscopy (5 patients), i.e. $15.9 \%$ of those hospitalized. The mean age of the patients was $48 \pm 14$ years with extremes of 15 and 84 years. The sample consisted of $59.2 \%$ men versus $40.8 \%$ women, for a sex ratio of 1.5 . The functional signs are in order of frequency: vomiting $(72.4 \%)$, anorexia (51.3\%) and epigastralgia (48.7\%). Terminal CKD by creatinine clearance accounted for $88.2 \%$ of cases, of which $47.4 \%$ were monitored by hemodialysis. Hepatitis C virus infection was present in $21.3 \%$ of cases, hepatitis B (18\%)
\end{abstract}


and HIV (7.5\%). Endoscopic examinations were represented by fibroscopy $(84.5 \%)$, rectoscopy $(8.5 \%)$ and anuscopy $(7 \%)$. The fibroscopic lesions were respectively gastric $(96.8 \%)$, duodenal $(14.1 \%)$ and esophageal (12.5\%). They were dominated by gastritis $(40.5 \%)$, duodeno-gastric reflux (16.4\%), pyloric gap (12.6\%). Rectoscopy found 4 cases of hemorrhoids, 2 cases of rectitis and no lesions were observed at anuscopy. Conclusion: The prevalence of these digestive manifestations and the endoscopic lesions encountered indicate the importance of digestive endoscopy and the performance of hepatic serologies in chronic renal failure patients with digestive symptoms and/or treated by hemodialysis.

\section{Keywords}

Chronic Renal Failure, Digestive Signs, Mali

\section{Introduction}

Chronic kidney disease (CKD) is the progressive and irreversible loss of kidney function. It results from the reduction of functional renal parenchyma. Its diagnosis is based on a decrease in glomerular filtration rate (GFR), which results in a progressive increase in plasma creatinine concentrations [1] [2]. It exposes to many complications, among which, digestive complications. Patients with CKD often have digestive manifestations, the frequency of which increases with the severity of the CKD [3].

There is a change in gastric secretion which may be related to the observed digestive lesions. According to some authors, the frequency of these lesions has halved since the advent of anti-secretory drugs [4] [5].

The prevalence of digestive lesions observed in a study conducted by Sawadogo $\mathrm{N}$ in Burkina Faso in the Yalgado Ouédraogo National Hospital Center (CHNYO) in 2002 [6] was 72.9\%, Ahmed [7] in Pakistan and Kochhar [8] in India found $68.3 \%$ and $68 \%$ of patients with digestive lesions respectively. These digestive complications aggravate the symptoms of renal failure and often contribute to its accutisation due to potentially nephrotoxic therapeutics and undernutrition.

In Mali, we do not have data on the prevalence of digestive pathologies in patients with chronic renal failure, hence the interest of this study.

Objective: To determine the prevalence of digestive pathologies and to describe their manifestations during chronic renal failure.

\section{Patients and Methods}

This was a prospective cross-sectional study conducted from September 2016 to August 2017, a period of 12 months. Included were patients with chronic renal failure who were hospitalized in the nephrology and hemodialysis department, consented and had undergone digestive endoscopy and/or liver serology. 
Patients with non-consensual CKD and/or incomplete medical records were excluded. Medical records and patient survey forms were used for data collection. The variables studied were:

- Socio-demographic data,

- The reason(s) for hospitalization,

- The patient's personal and collateral history,

- The data from the physical examination,

- Paraclinical examination data.

Chronic renal failure has been defined as a persistent (greater than 3 months) decline in creatinine clearance $\left(<60 \mathrm{ml} / \mathrm{min} / 1.73 \mathrm{~m}^{2}\right)$ according to the CK-EPI formula, associated with a decrease in kidney size $(<90 \mathrm{~mm})$ with cortico-sinusal dedifferentiation, normocytic normocyticanaemia, hypocalcaemia + hyperphosphatemia.

Ethical consideration: the free and informed consent of each participant in the study or one of his close relatives was obtained with strict respect for the anonymity of the survey form.

The data entry and statistical analysis were carried out using Word 2007 and SPSS 20 French version. The $\mathrm{Chi}^{2} \mathrm{t}$-test was used for the entire study, values of $\mathrm{p}$ $<0.05$ were considered significant.

\section{Results}

During the study period, 478 patients were hospitalised in the Nephrology and haemodialysis department of CHU Point G, 71 of whom benefited from digestive endoscopy using oesogastroduodenalfibroscopy (60 patients), rectoscopy (6 patients) and anoscopy (5 patients), i.e. 15.9\% of the patients hospitalised. Among 76 patients, $80.2 \%$ performed viral serology (HBV, HCV, HIV) and $64.5 \%$ performed endoscopy and viral serology. The mean age of the patients was $48 \pm 14$ years with extremes of 15 and 84 years. The sample consisted of $59.2 \%$ men versus $40.8 \%$ women, for a sex ratio of 1.5 . Impaired renal function accounted for $90.8 \%$ of the reasons for consultation. The functional signs are in order of frequency: vomiting (72.4\%), anorexia (51.3\%) and epigastralgia (48.7\%) (See Table 1). The frequency of anaemia was $98.7 \%$ with a mean $\mathrm{Hb}$ level of $7.6 \mathrm{~g} / \mathrm{dl}$ with extremes of $3.5 \mathrm{~g} / \mathrm{dl}$ and $12.2 \mathrm{~g} / \mathrm{dl}$, it was severe (haemoglobin level less than $6 \mathrm{~g} / \mathrm{dl}$ ) in $23.7 \%$. Hypocalcaemia is observed in $84.2 \%$ of cases. In $72.4 \%$ of cases, the kidneys are small and undifferentiated. Terminal CKD by creatinine clearance accounted for $88.2 \%$ of cases, of which $47.4 \%$ were monitored by hemodialysis. The causes of CKD are, in order of frequency, vascular (44.7\%), tubulo-intertitial (20.1\%), glomerular (19\%), diabetic (9\%) and indeterminate (7\%). Hepatitis C virus infection was present in $21.3 \%$ of cases (see Table 2). Endoscopic examinations were represented by fibroscopy (84.5\%), rectoscopy $(8.5 \%)$ and anuscopy (7\%). The fibroscopic lesions were respectively gastric (96.8\%), duodenal (14.1\%) and esophageal (12.5\%), (Cf. Table 3). They were dominated by gastritis $(40.5 \%)$, (Figure 1 ). The severity of renal failure increases 
Table 1. Distribution of patients according to digestive signs.

\begin{tabular}{ccc}
\hline Digestive signs & Staff & Percentage \\
\hline Vomiting & 55 & 72.4 \\
Anorexia & 39 & 51.3 \\
Epigastralgia & 37 & 48.7 \\
Nausea & 19 & 25 \\
Diarrhoea & 13 & 17.1 \\
Constipation & 8 & 10.5 \\
Hiccup & 7 & 9.2 \\
Meteorism & 5 & 6.6 \\
Haematodesis & 4 & 5.3 \\
Ascite & 4 & 5.3 \\
Méléna & 4 & 5.3 \\
Gingivorrhagia & 1 & 1.3 \\
\hline
\end{tabular}

Vomiting was observed in $72.4 \%$ of our patients.

Table 2. Distribution of patients by HBV, HCV and HIV serology.

\begin{tabular}{cccc}
\hline Serological Balance Sheet & Positive & Negative & Total \\
\hline Serology AgHbs & $11(18 \%)$ & $50(82 \%)$ & $61(100)$ \\
HVC serology & $13(21.3 \%)$ & $48(78.7 \%)$ & $61(100)$ \\
HIV Serology & $4(7.5 \%)$ & $50(92.5 \%)$ & $54(100)$ \\
\hline
\end{tabular}

Hepatitis $C$ virus infection was present in $21.3 \%$ of cases.

Table 3. Distribution of patients according to lesions observed on fibroscopy.

\begin{tabular}{ccc}
\hline Endoscopic lesions & Staff & Percentage \\
\hline Esophageal Lesions & $\mathbf{8}$ & 10 \\
Esophageal Candidiasis & 3 & 3.8 \\
Peptic esophagitis & 3 & 3.8 \\
Pallor of the oesophagus & 2 & 2.5 \\
Gastric Lesions & $\mathbf{6 2}$ & $\mathbf{8 1}$ \\
Gastritis & 31 & 40.5 \\
Duodeno-gastric reflux & 13 & 16.4 \\
Pylorus Bean & 9 & 12.6 \\
Gastric Pallor & 5 & 6.3 \\
Gastric Ulcer & 3 & 3.8 \\
Gastric Cancer & 1 & 1.2 \\
Duodenal Lesions & 7 & 9 \\
Duodenite & 3 & 3.8 \\
Duodenal pallor & 2 & 2.5 \\
Duodenal Cancer & 1 & 1.2 \\
Duodenal Ulcer & 1 & 1.2 \\
\hline
\end{tabular}

Gastritis was the dominant lesion with $40.5 \%$. 
the frequency of fibroscopic lesions $(\mathrm{P}=0.001)$, (Cf. Table 4) and viral infections (Cf. Table 5). Rectoscopy found 4 cases of hemorrhoids, 2 cases of rectitis and no lesions were observed at anuscopy.

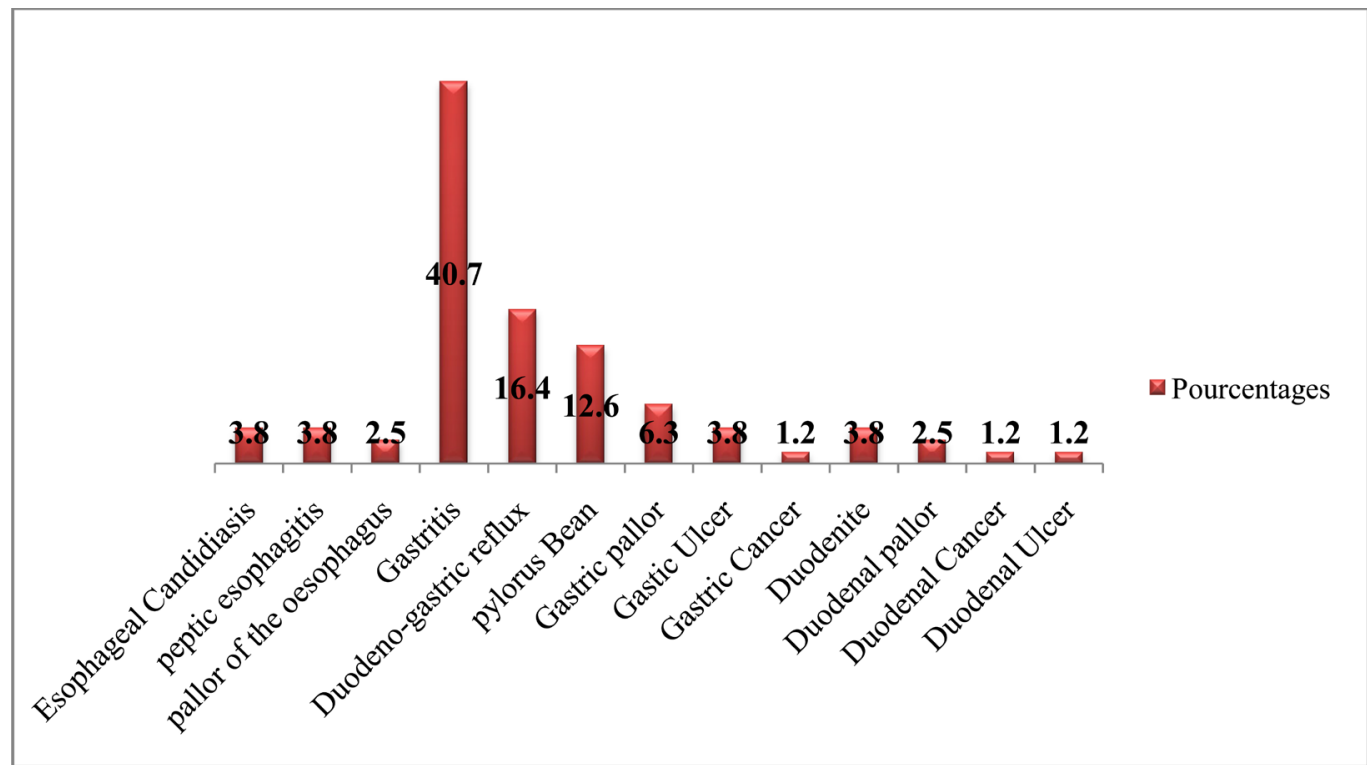

Gastritis was the dominant lesion with $40.7 \%$.

Figure 1. Distribution according to lesions on fibroscopy.

Table 4. Distribution of patients according to CKD stages and lesions on fibroscopy.

\begin{tabular}{ccccc}
\hline Endoscopic lesions & Stage 1 & Stage 2 & Stage 3 & Total \\
\hline Esophageal Lesions & 2 & 0 & 6 & $\mathbf{8}$ \\
Esophageal Candidiasis & 2 & 0 & 1 & 3 \\
Peptic esophagitis & 0 & 0 & 3 & 3 \\
Pallor of the oesophagus & 0 & 0 & 2 & 2 \\
Gastric Lesions & 2 & $\mathbf{3}$ & $\mathbf{5 7}$ & $\mathbf{6 2}$ \\
Gastritis & 2 & 2 & 28 & 31 \\
Duodeno-gastric reflux & 0 & 1 & 10 & 13 \\
Pylorus Bean & 0 & 0 & 10 & 9 \\
Gastric Pallor & 0 & 0 & 5 & 5 \\
Gastric Ulcer & 0 & 0 & 3 & 3 \\
Gastric Cancer & 0 & 0 & 1 & 1 \\
Duodenal Lesions & 0 & 2 & $\mathbf{5}$ & $\mathbf{7}$ \\
Duodenite & 0 & 2 & 1 & 3 \\
Duodenal pallor & 0 & 0 & 2 & 2 \\
Duodenal Cancer & 0 & 0 & 1 & 1 \\
Duodenal Ulcer & 0 & 0 & 1 & 1 \\
\hline
\end{tabular}

Esophageal candidiasis and duodenitis were common in end-stage CKD. Esophageal candidiasis: $\mathrm{X}^{2}=39.3$ $\mathrm{ddl}=2 ; \mathrm{P}=0.001$. Duodenite: $\mathrm{X}^{2}=14 ; \mathrm{ddl}=2 ; \mathrm{P}=0.01$. 
Table 5. Breakdown of patients by CKD stage and viral liver serology.

\begin{tabular}{cccc}
\hline \multirow{2}{*}{ IRC Stadiums } & \multicolumn{3}{c}{ Viral liver serology } \\
\cline { 2 - 4 } & Hepatitis B & Hepatitis C & HIV \\
\hline Moderate Stage & $1(9 \%)$ & $1(7 \%)$ & $1(25 \%)$ \\
Severe Stadium & $2(18 \%)$ & $0(0 \%)$ & $1(25 \%)$ \\
Terminal Stadium & $8(72 \%)$ & $12(92 \%)$ & $2(50 \%)$ \\
Total & $11(100 \%)$ & $13(100 \%)$ & $4(100 \%)$ \\
\hline
\end{tabular}

The rate of viral infection increases with the stage of kidney failure. $\mathrm{X}^{2}=6.18 ; \mathrm{ddl}=4 ; \mathrm{P}=0.51$.

\section{Discussion}

Study Limitations: Patients whose general condition did not allow for GI endoscopy and who did not perform liver serology and those who did not consent were not included in the study. These have contributed to the reduction of our workforce.

The mean age of the patients was $48 \pm 14$ years with extremes of 15 and 84 years. The 50 - 70 age group was the most represented with $43.4 \%$ of patients. In the literature, Varma [9] in India, David etcollaborateurs [10] in the USA, Rey et collaborateurs [11] in France, Gary and Zuckerman in the USA [12] reported an average age in $42.26,43.1,50.1$ and 57 years respectively. Low life expectancy, socio-economic conditions, diet and the high frequency of predisposing pathologies (hypertension, diabetes) could also explain this difference. The sample was composed of $59.2 \%$ men versus $40.8 \%$ women, for a sex ratio of 1.5 . This male dominance is classic in literature [9] [11] [13]. It may be explained by a higher incidence of kidney disease and its more rapid progression to end-stage renal disease in men [14]. Impaired renal function accounted for $90.8 \%$ of the reasons for consultation. In Côte d'Ivoire Diallo A found MTA as the reason for consultation (40.83\%), followed by alteration in general condition (12.23\%) [15]. Thefunctional signs are in order of frequency: vomiting (72.4\%), anorexia (51.3\%) and epigastralgia (48.7\%). In Burkina Fasso, Lengani et al. reported vomiting in $63 \%$ of patients [16]. The high frequency of vomiting and anorexia in our study could be explained by the severity of CKD. Reported in the literature, vomiting may be secondary to or induce hydroelectrolytic disorders (hyponatremia), creating a vicious circle with aggravation of impaired renal function. It can therefore be seen that functional digestive signs such as nausea, vomiting and anorexia become more frequent as the CKD progresses. This observation has been made by other authors Varma and Rey [9] [11]. The prevalence of hepatitis B and $\mathrm{C}$ in haemodialysis patients varies from country to country but remains higher than in the general population (HCV: $2.7-22.2 \%$ in the DOPPS registry). In our series the seroprevalence of hepatitis $C$ is high at $18.1 \%$ but remains lower than that reported in other Moroccan studies $53.3 \%$ in Rabat and 78\% in Casablanca) [17] [18], and that of HbsAg at $15.3 \%$ with a range of $1.63 \%$ to $15 \%$ provided by the literature. These prevalences can be explained by the age of dialysis, 
multiple blood transfusions, nosocomial transmission through non-compliance with individual and collective hygiene rules and the alteration of the immune defences induced by chronic renal failure. The prevalence of HIV infection was very low, in our series the risk of transmission of HIV infection from one patient to another was almost zero subject to strict hygiene rules. Digestive endoscopy was pathological in $84.3 \%$ of the patients studied. Ahmed in Pakistan [7] and Kochhar [8] reported $68.3 \%$ and $68 \%$ of pathological endoscopies respectively.

Endoscopic lesions in order of frequency were gastric (96.8\% of patients), followed by duodenal (14.1\% of patients) and esophageal (12.5\% of patients). This predominance of gastric lesions has been found by other authors, Varma [9], Rey [11], on the other hand, it was duodenal in the study of Kochhar [8]. These lesions could be explained by the increased acid secretion in the gastric and duodenal tracts of patients with chronic renal failure [19]. The incidence of esophageal fungal infections was $3.8 \%$. In the literature, it has been observed that esophageal mycoses can complicate certain medical conditions including CKD. In our study, HIV infection could explain the high frequency of esophageal mycoses $(\mathrm{P}=0.009)$.

\section{Conclusion}

The prevalence of these digestive manifestations and the endoscopic lesions encountered indicate the importance of digestive endoscopy and the performance of liver serology in patients with chronic renal failure presenting digestive symptoms and/or treated by hemodialysis.

\section{Conflicts of Interest}

The authors declare no conflicts of interest regarding the publication of this paper.

\section{References}

[1] Bernard, L. and Ziad, M. (2013) Diagnosis, Biological Monitoring of Chronic Renal Failure and Management of End-Stage Renal Disease. Revue Française des Laboratoires, 451, 59-72.

[2] Combe, C., Kourilsky, O., Kanfer, A. and Peraldi, M.N. (2014) Nephrology and Hydroelectrolytic Disorders. Elsevier Masson SAS, Paris.

[3] Thierry, H., François, C. and Eveline, F. (2001) Diagnostic Approach to Early-Stage Chronic Kidney Disease. La Revue du Praticien, 51, 372-377.

[4] Benzo, J., Matos, M., Milanes, C., Aarminio, A. and Stempel, C. (1994) Endoscopic Findings in the Upper Digestive Tract in Patients with Terminal Chronic Kidney Failure. Gen, 48, 34-38.

[5] Mignon, M., Cadiot, G. and Soule, J. (2001) Pathophysiology of Gastric Secretion during Chronic Renal Failure. Kidney and Digestive Tract 23rd Symposium, Gambo, September 2001, 1-11.

[6] Sawadogo, N. (2002) Upper Digestive Manifestations and Severe Chronic Renal Failure in the $\mathrm{C}$ Medicine Department of the Yalgado Ouédraogo National Hospital Center (CHNYO). Thèse Med, Ouagadougou. 
[7] Ahmed, W., Qureshi, H., Zuberi, S.J., Naqvi, A.J., Mahmood, S. and Rafig, N. (1993) Endoscopielésions in Chronic Renal Failure. Journal of Pakistan Medical Association, 43, 95-96.

[8] Kochar, R., Gupta, K.L., Malik, A.K., et al. (1988) Morphological Alteration of Upper Gastrointestinal in Uraemic Patient. Indian Journal of Gastroenterology, 7, 149 150.

[9] Varma, P.P., Prasher, P.K., Pruthi, H.S., et al. (1996) Upper Gastrointestinal Bleeding in Chronic Renal Failure. Indian Journal of Nephrology, 6, 150-152.

[10] Margolis, D.M., Saylor, J. and Guiller, M. (1978) Upper Gastrointestinal Disease in CRF: A Prospective Evaluate. Archives of Internal Medicine, 138, 1214-1217. https://doi.org/10.1001/archinte.1978.03630330014007

[11] Rey, J.F., Lombart, J., Bournerie, A. and Salvadori, J.M. (1982) Interest of Upper GI Fibroscopy in CKDs Treated with Iterative Hemodialysis. Sem Hop Paris, 13, 782-792.

[12] Gary, R., Zuckerman, D., Gary, L. and Cornette, R. (1985) Upper Gastrointestinal Bleeding in Patients with CRF. Annals of Internal Medicine, 102, 588-598. https://doi.org/10.7326/0003-4819-102-5-588

[13] Chalasni, N., Costsonis, G. and Wilcox, C.M. (1996) Upper Gastrointestinal Bleeding in Patients with CRF Role of Vascular Ectasia. American Journal of Gastroenterology, 91, 2329-2332.

[14] Pouteil-noble, C. and Emmanuel, V. (2001) Epidemiology and Etiology of Chronic Renal Failure. La Revue du Praticien, 51, 365-371.

[15] Diallo, A., Niamkey, E. and Beda, B.Y. (1997) Chronic Renal Failure in Côte d'Ivoire Study of 800 Hospitalized Cases. Bulletin de la Société de Pathologie Exotique, 90, 346-348.

[16] Lengani, A., Coulibaly, G., Laville, M. and Zech, P. (1997) Epidemiology of Severe Chronic Renal Failure in Burkina Faso. Sante, 7, 379-383.

[17] Boulaajaj, K., Elamaro, Y. and Elmalki, B. (2005) Viral Infections: HCV, HBV, HIV in Hemodialysis CHU Ibn-Rochd Casablanca. Néphrologie \& Thérapeutique, 1, 174-184. https://doi.org/10.1016/j.nephro.2005.06.012

[18] Benamar, L., Rhou, H., Ezzaitouni, F. and Bayahya, R. (2001) Viral Hepatitis C in Chronic Haemodialysis at the Rabat University Hospital Prevalence and Risk Factors. Med Maghreb, 8, 43-49.

[19] Shepart, A.M.M., Stewart, W.K. and Worley, K.G. (1973) Peptic Ulceration in Chronic Renal Failure. The Lancet, 1, 1357-1359.

https://doi.org/10.1016/S0140-6736(73)91677-2 